\title{
Radiological imaging and orthodontic treatment in the case of growing patients after oncological treatment: Case reports
}

\section{Obraz radiologiczny i postępowanie ortodontyczne w przypadku rosnących pacjentów po leczeniu onkologicznym - opis przypadków}

\author{
${ }^{1}$ Maestria Digital Dental and Face Clinic, Warszawa, Poland \\ ${ }^{2}$ Department of Orthodontics, Faculty of Medicine and Dentistry, Medical University of Warsaw, Poland \\ ${ }^{3}$ Pediatric Dentistry Clinic, Medical Center in Marki, Poland \\ ${ }^{4}$ Be Active Dentist Organization, Kozienice, Poland \\ A - research concept and design; $\mathrm{B}$ - collection and/or assembly of data; $\mathrm{C}$ - data analysis and interpretation; \\ $D$ - writing the article; $E$ - critical revision of the article; $F$ - final approval of the article
}

Izabela Michalak ${ }^{1, A-D}$, Dorota Kuśmierczyk ${ }^{2, C, E, F}$, Katarzyna Bluj-Komarnitka ${ }^{3, A, D}$, Sadri Rayad ${ }^{4, A}$, Małgorzata Zadurska ${ }^{2, E, F}$

\section{Address for correspondence}

Izabela Michalak

E-mail: izabelawieclaw@gmail.com

Funding sources

None declared

Conflict of interest

None declared

Received on January 17, 2019

Reviewed on March 7, 2019

Accepted on March 26, 2019

Published online on May 10, 2019

Cite as

Michalak I, Kuśmierczyk D, Bluj-Komarnitka K, Rayad S, Zadurska M. Radiological imaging and orthodontic treatment in the case of growing patients after oncological treatment: Case reports. Dent Med Probl. 2019;56(2):209-215. doi:10.17219/dmp/105958

D0I

$10.17219 / \mathrm{dmp} / 105958$

Copyright

○ 2019 by Wroclaw Medical University

This is an article distributed under the terms of the

Creative Commons Attribution 3.0 Unported License (CC BY 3.0)

(https://creativecommons.org/licenses/by/3.0/)

\begin{abstract}
According to the classification of the World Health Organization (WHO), the most common childhood malignant neoplasms include leukemia, lymphomas, and neoplasms of the central nervous system (CNS) and the sympathetic nervous system. Cancer diseases themselves as well as their treatment carry a high risk of both early and distant effects.

The most common dentition disorders resulting from the radiotherapy of the head area and chemotherapy in patients up to the age of 6 years include root agenesis, V-shaped roots, microdontia, hypoplasia of the maxilla and the jawbone, hypodontia, and enamel hypoplasia and hypomineralization.

Patients undergoing oncological treatment at the age of $<6$ years should receive adequate and long-term monitoring due to the possible distant effects of the underlying disease and its treatment. The radiotherapy of the head and neck region performed on a growing patient significantly worsens the patient's prognosis and results in a number of irreversible complications.

Planning appropriate orthodontic treatment in such patients contributes to increased comfort later in the patients' lives. Oncology patients do not require special orthodontic procedures; however, the high risk of complications does encourage the planning of orthodontic treatment with the least burden. Dental care for a young patient with a history of oncological disease requires the interdisciplinary cooperation of a pedodontist, orthodontist, prosthetist, and dental surgeon.
\end{abstract}

Key words: chemotherapy, radiotherapy, dental abnormalities, pediatric oncology

Słowa kluczowe: chemioterapia, radioterapia, nieprawidłowości zębowe, onkologia dziecięca 


\section{Introduction}

The World Health Organization (WHO) and the International Classification of Childhood Cancer (ICCC) state that the most common childhood neoplastic diseases include leukemia, Hodgkin's lymphomas, non-Hodgkin's lymphomas, central nervous system (CNS) tumors, and tumors of the sympathetic nervous system. Childhood tumors are rare, affecting 1 in 600 children during the first 15 years of life. ${ }^{1}$ Early diagnosis and effective therapy of an oncological disease provides the patients with a chance for long-term survival. ${ }^{2}$

The main methods of treatment used in pediatric oncology include surgery, irradiation and chemotherapy. The use of combined treatment, conducted according to the latest standards of cancer treatment, increases the chances for treatment success and improves the survival rates during the developmental period after the oncological disease. ${ }^{3}$ Both radiotherapy and chemotherapy demonstrate a number of side effects, causing damage to soft tissues and to the respiratory, cardiovascular, skeletal, and hormonal systems. ${ }^{4}$ The destructive effect on the teeth at the developmental stage is also well-known. The complications of oncological therapy include tooth agenesis, root underdevelopment, V-shaped roots, microdontia, hypodontia, and tooth eruption disorders. These complications have a significant adverse effect on the patient's quality of life after treatment, and their severity often correlates with the intensity of therapy and the developmental stage of the patient. ${ }^{5-8}$

Tooth development is a long-term process which can be subject to internal and external factors. Amelogenesis and dentinogenesis may be disturbed by radiation when a beam is directed at the oral cavity or its surroundings. The teeth that are positioned along the radiation beam receive $45 \%$ of the administered dose. ${ }^{9}$ However, radiation directed at distant areas of the body does not have a significant effect on the development of the teeth. According to Dahllöf et al., the radiation dosage which induces histological changes in the developing permanent tooth bud is $10 \mathrm{~Gy} \cdot{ }^{10}$ High doses of radiation result in the death of ameloblasts and odontoblasts, regardless of their stage in the cell cycle. The development of dental tissues is suppressed, therefore the partially formed teeth, due to root agenesis, remain in the bone. ${ }^{11}$

The effects of direct irradiation of bones, soft tissues and blood vessels are dose-dependent and are most prominent in fast-growing patients (children under 6 years of age and children during puberty). Impaired blood supply to these areas may lead to osteoradionecrosis, but this disorder is rare in juvenile patients. ${ }^{12}$

Irradiation of CNS may inhibit the hypothalamic-pituitary function, resulting in reduced production of growth hormone and thyroid-stimulating hormone. Consequently, this may adversely affect odontogenesis and craniofacial development, causing asymmetrical facial bone growth, for example. Growth disorders and symptoms of premature puberty have also been observed. ${ }^{13,14}$
The short-term side effects of chemotherapy include cytotoxicity, bone marrow suppression, increased susceptibility to infection, xerostomia symptoms, more cariogenic bacteria in the oral cavity, and increased susceptibility to periodontal diseases and fungal infections. ${ }^{15}$ The long-term complications of chemotherapy, reported in the literature, include missing tooth buds, microdontia, tooth crown hypoplasia, deficient enamel mineralization, and disturbed formation of the tooth root. ${ }^{15-17}$ Chemotherapy-induced dental anomalies occur when the patient is treated before the age of 6 years. The degree of damage to the teeth and bones depends on the patient's age, and the type and duration of chemotherapy.

Despite these documented threats of temporary or permanent side effects, cancer treatment must be applied as a life-saving or necessary procedure for the patient. Modern methods of cancer treatment significantly increase the survival rates, which means that an increasing number of children are referred for orthodontic treatment after their cancer treatment. ${ }^{18,19}$ The appropriate diagnosis of abnormalities, both systemic and local, helps in planning the proper treatment of any complications, including orthodontic ones, in oncological patients. ${ }^{20}$ The management of patients affected by the complications in the masticatory system resulting from chemotherapy and radiotherapy is not significantly different from routine orthodontic procedures, yet it must take into account any existing disorders.

\section{Case presentation}

\section{Case 1}

At the age of 2 years, Patient B.D. was diagnosed with embryonal rhabdomyosarcoma, which was present in the nasal part of the throat, the paranasal sinuses, and partially in the orbits and the middle cranial fossa.

Due to the extent of the tumor, the patient was at first treated with chemotherapy, followed by surgical treatment, involving a partial removal of the neoplastic lesion. Subsequently, the chemotherapy continued along with the irradiation of the tumor-affected area, the sphenoidal sinus and the nasopharynx at a dose of up to $5.4 \mathrm{cGy} /$ week. The treatment was completed in 2015.

The patient reported to the Department of Orthodontics at the Medical University of Warsaw (Poland) at the age of 8,3 years after the end of cancer treatment (Table 1 , Fig. 1-4).

Treatment with an orthodontic block appliance was planned at the first stage based on a clinical examination, and the analysis of diagnostic models and radiological scans. The construction bite was done at a 3-millimeter gap between the front teeth. The patient used the block appliance for $3 \mathrm{~h}$ during the day and overnight in order to relieve the front teeth and to increase the range of mandible abduction (Fig. 5). 
Table 1. Examination of the patient, Case 1

Case 1

Examination of the patient

Extraoral

- asymmetry of the middle and lower face

(eye socket, mouth corners and palpebral fissures)

- hypoplasia of the maxilla and the mandible

- shortened lower face
- reduction of mandibular abduction to $25 \mathrm{~mm}$

- pink, moist mucous membrane

- marginal gingivitis

- present teeth: $21,22,26,31,32,36,41,42,46,63,73$, and 83

- tooth 21 with pathological mobility (3 $3^{\text {rd }}$ degree)

- significant demineralization of the enamel (white and dark spots)

Radiological status at the age of 7 ( 2 years after the completion of cancer therapy)

- a lack of buds for teeth $15,25,45,35,37$, and 47

- a complete lack of roots for teeth $11,12,21,22,23,13,14,24,16,26$, and 46 (the apical foramen closed - inhibition of development)

- delayed tooth root development diagnosed in relation to teeth 41, 42, 31, 32, 33, 43, 34, 44, and 36 with the apical foramen open

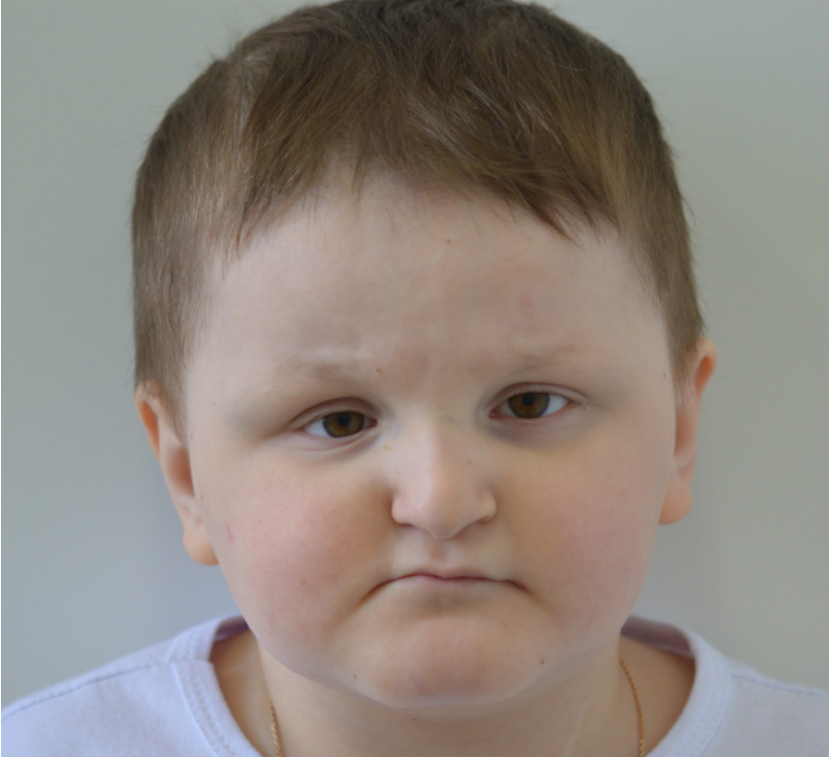

Fig. 1. Extraoral photo of patient B.D.

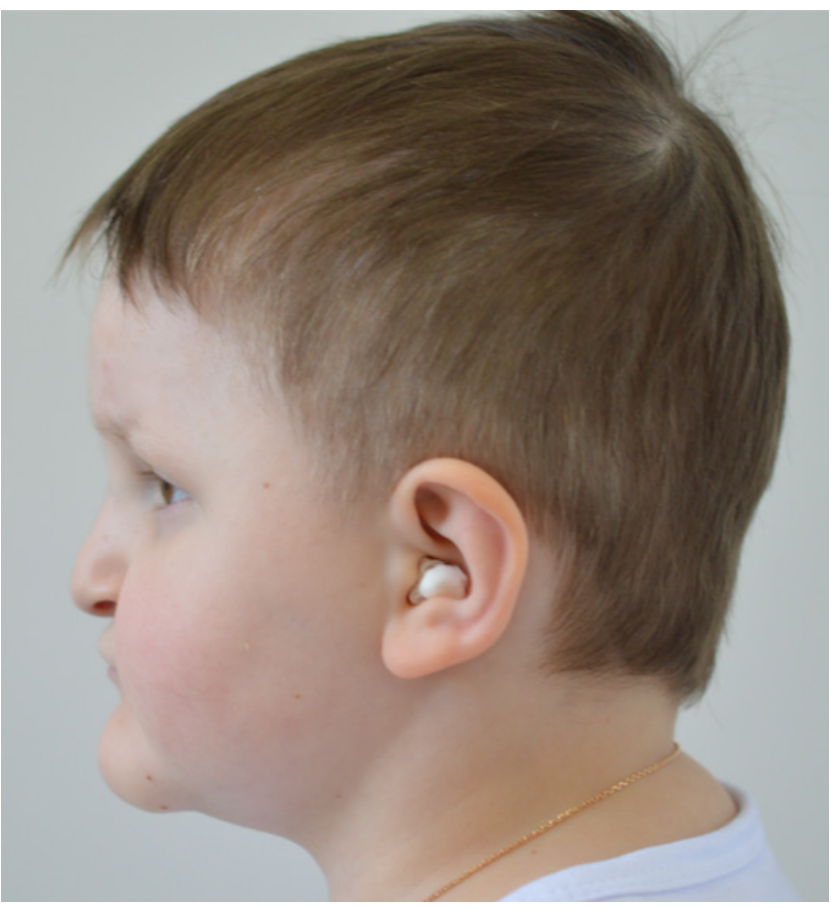

Fig. 2. Profile photo of patient B.D

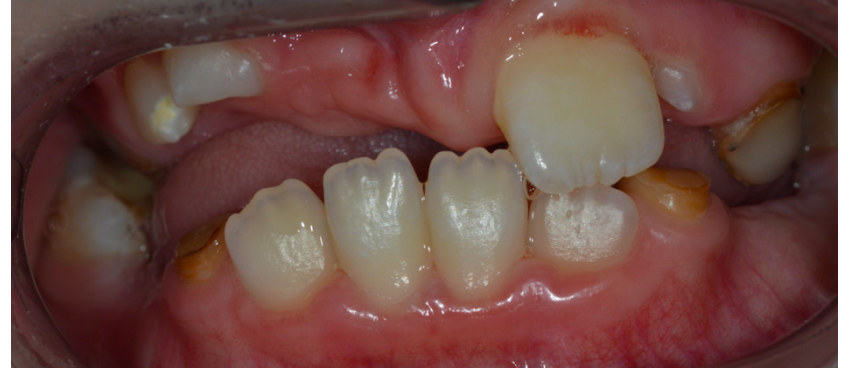

Fig. 3. Intraoral photo of patient B.D.

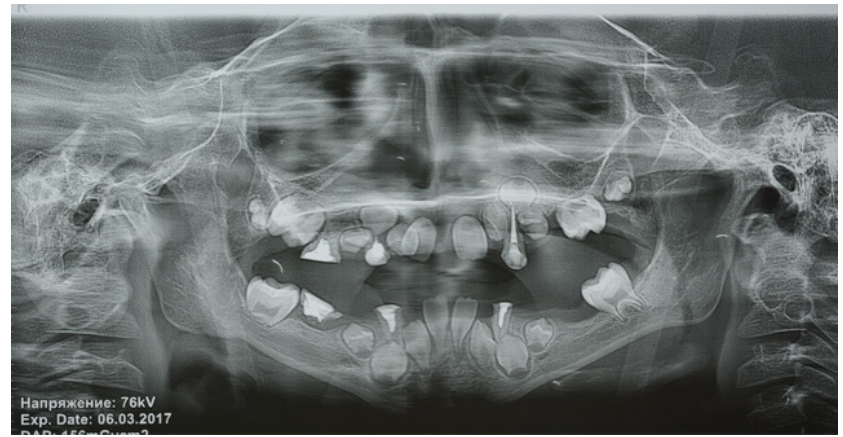

Fig. 4. Panoramic X-ray of patient B.D. at the age of 7

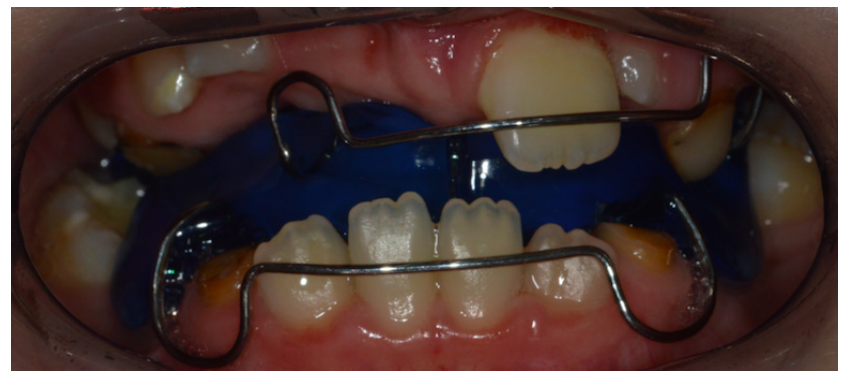

Fig. 5. Block appliance of patient B.D.

The patient's guardian was informed about the high risk of losing the permanent teeth with aplastic roots and the possibility of future prosthetic treatment. At follow-up, after 6 months of treatment with an orthodontic appliance, the range of mandible abduction had improved to $33 \mathrm{~mm}$. 


\section{Case 2}

Patient J.G. was diagnosed with stage 4 Burkitt's lymphoma at the age of 4 years. Burkitt's lymphoma is a nonHodgkin's lymphoma originating from B lymphocytes. The patient had neoplastic lesions in the abdominal cavity, which had additionally infiltrated the craniofacial bones and the thyroid gland. The cancer treatment included 10 months of chemotherapy (Table 2, Fig. 6-9).

Due to the low risk of complications, good overall health and the lack of other contraindications, it was possible to start orthodontic treatment earlier than after the normally required 2-year period since the completion of the oncological therapy. The first stage of treatment consisted in the preparation of child prostheses in order to restore the biting and chewing functions, to improve

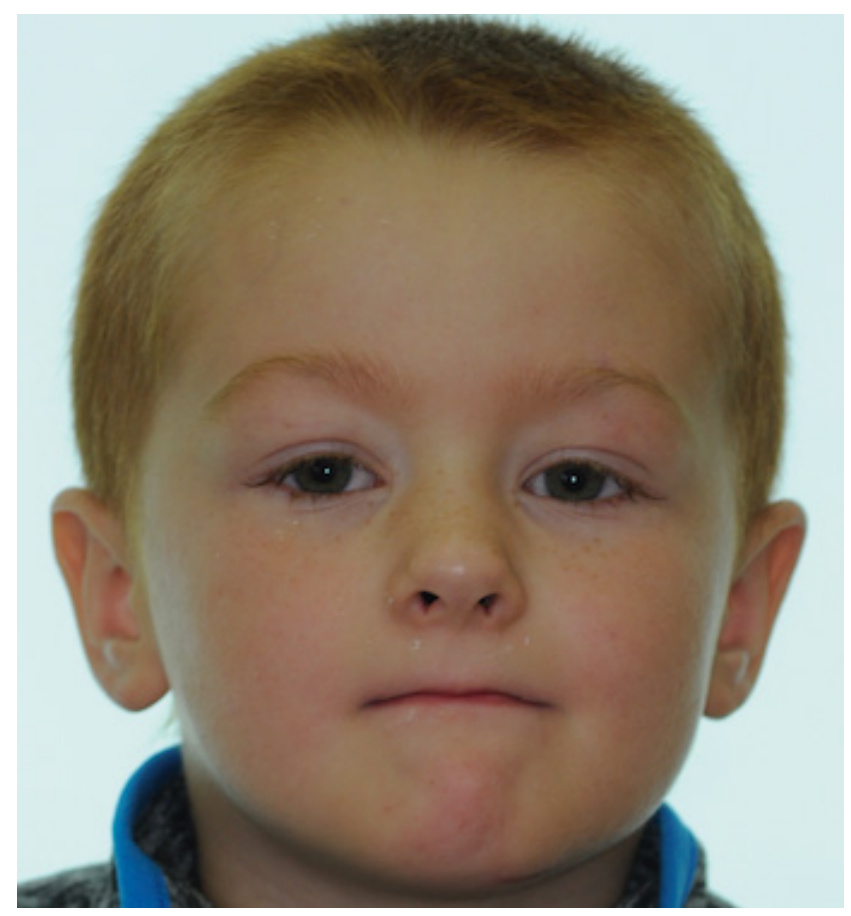

Fig. 6. Extraoral photo of patient J.G. esthetics and to enable better pronunciation. The alveolar process of the maxilla and the alveolar part of the mandible showed signs of significant atrophy, resulting in unfavorable conditions for prosthetics. The patient's cooperation was limited, which made it difficult to perform clinical procedures (Fig. 10-12).

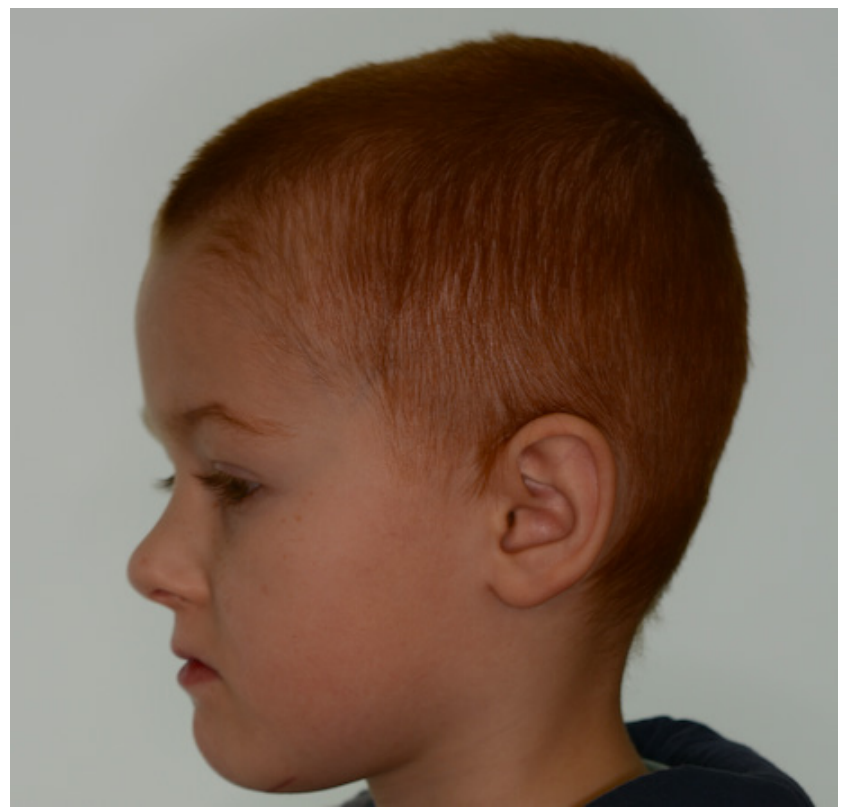

Fig. 7. Profile photo of patient J.G.

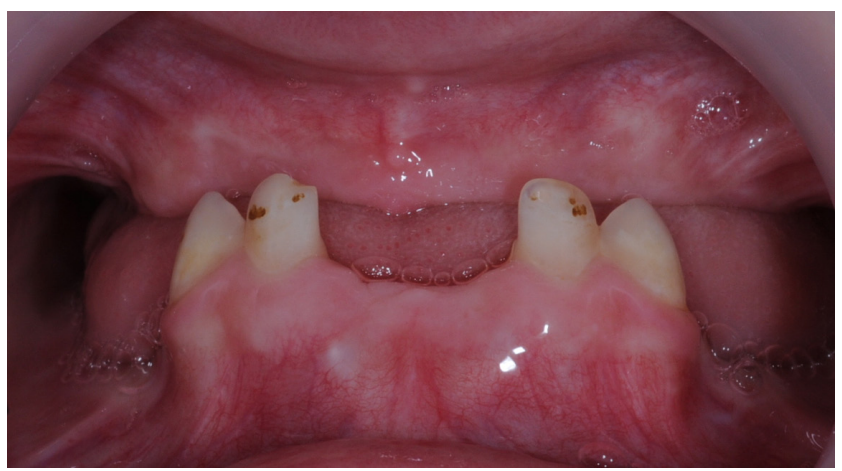

Fig. 8. Intraoral photo of patient J.G.

Table 2. Examination of the patient, Case 2

\section{Case 2}

\begin{tabular}{|c|c|}
\hline \multicolumn{2}{|c|}{ Case 2} \\
\hline \multicolumn{2}{|c|}{ Examination of the patient } \\
\hline Extraoral & Intraoral \\
\hline $\begin{array}{l}\text { - } \text { preserved facial symmetry } \\
\text { - sunken subnasal region } \\
\text { - shortened lower face }\end{array}$ & $\begin{array}{l}\text { - extensive dental deficiencies (present teeth: } 72,73,82 \text {, and } 83 \text { ) } \\
\text { - small spots of enamel demineralization } \\
\text { - significant atrophy of the alveolar process of the maxilla and the alveolar } \\
\text { part of the mandible } \\
\text { - normal mucous membrane }\end{array}$ \\
\hline \multicolumn{2}{|c|}{ Radiological status at the age of 6 ( 2 years after the completion of cancer therapy) } \\
\hline \multicolumn{2}{|c|}{$\begin{array}{l}\text { - a lack of buds in the case of permanent teeth } 45 \text { and } 15 \\
\text { - } \text { delayed development of the roots of the permanent teeth (narrow, V-shaped roots) } \\
\text { - } \text { buds of teeth } 36 \text { in Demirjian's developmental stage } F \\
\text { - teeth } 41,42,31 \text {, and } 32 \text { and } 47 \text { in Demirjian's stage } C \text { show signs of enamel formation on the chewing surface, small amounts of dentin are visible } \\
\text { - teeth } 43,33,34,34,25,24,45 \text {, and } 14 \text { show the beginning of root formation, corresponding to Demirjian's stage D }\end{array}$} \\
\hline
\end{tabular}




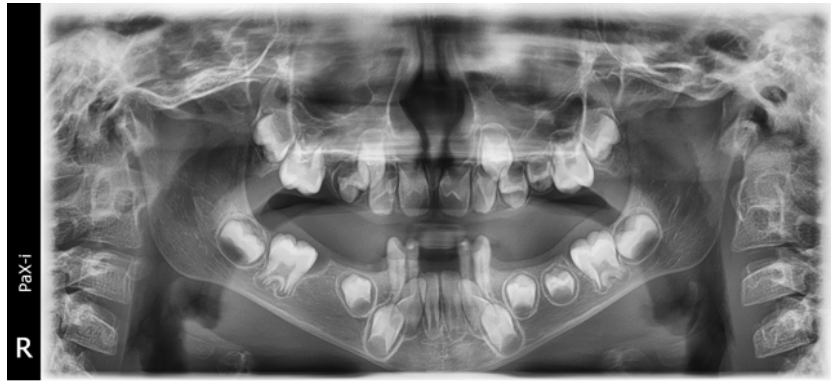

Fig. 9. Panoramic X-ray of patient J.G. at the age of 6

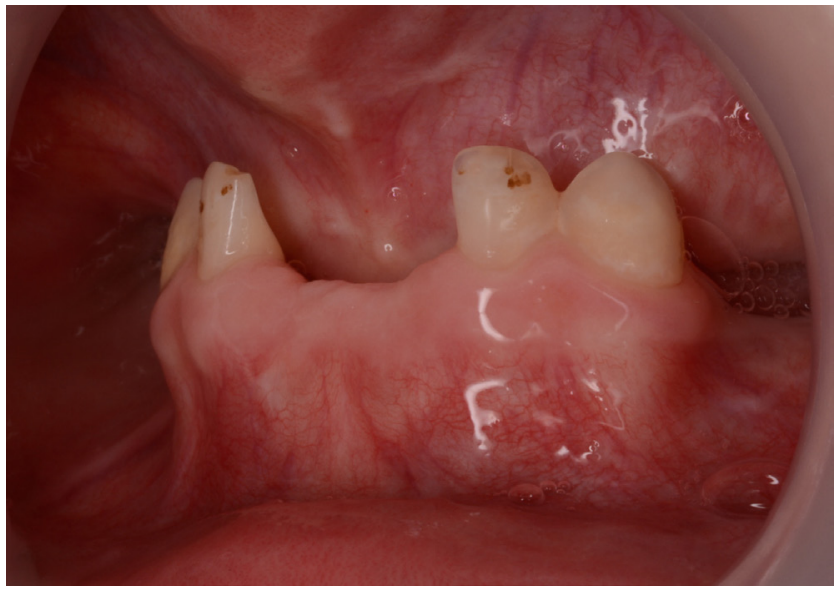

Fig. 10. Intraoral photo of the condition of the maxilla and the madible of patient J.G.

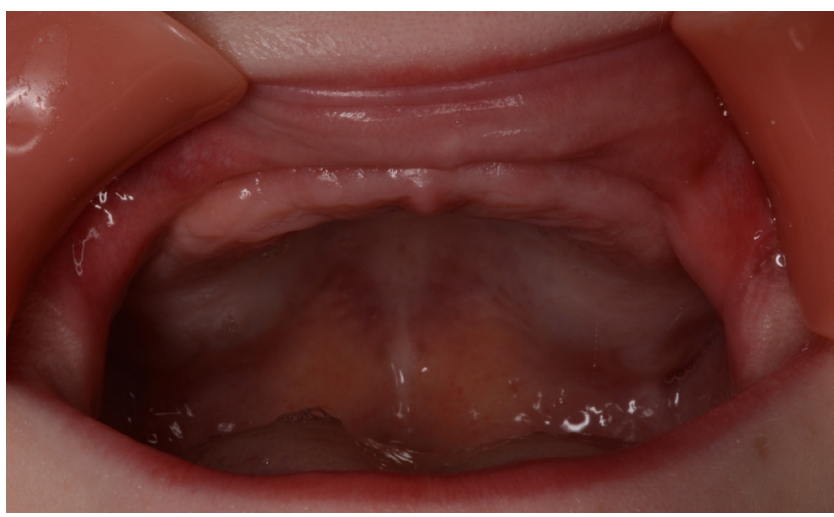

Fig. 11. Intraoral photo of the maxilla of patient J.G.

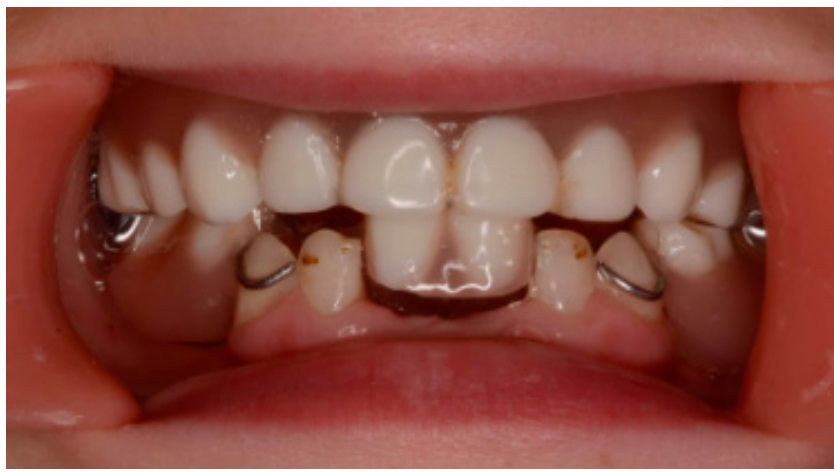

Fig. 12. Patient J.G. with the appliance after 6 months of use. Lack of proper stability of the appliance
After 6 months of treatment, the lower appliance showed poor stability due to the growth of the patient and the eruption of the molars. At follow-up at the age of 7 , the eruption of teeth 46, 36 and 26 had begun, with minor signs of disturbed enamel mineralization in the form of small white spots.

\section{Discussion}

When planning orthodontic treatment of a patient with a history of a neoplastic disease, it is important to work with their oncologist. The patient's health status and prognosis should be considered in their therapy.

The following factors of an increased risk of complications are mentioned in the literature: cancer diagnosis at the age of $<8$ years, radiotherapy of the entire body or of the head and neck (with a dose of over 2.4 cGy), a diagnosis of a solid tumor (located in the craniofacial region, in particular), hypothyroidism, hypopituitarism, $<2$ years passed since the end of chemotherapy or radiotherapy, stem cell transplantation, abnormal development of the tooth root, and gingival hypertrophy after treatment with drugs such as cyclosporin A. ${ }^{21,22}$ In the literature, there can be found recommendations to start orthodontic treatment at least 2 years after cancer therapy has finished, when the patient's oncological disease is in a state of permanent remission. The recommended withdrawal period was maintained when treating the patients presented herein. When performing extractions due to orthodontic indications, the 24-month waiting period should be observed because of the increased risk of osteonecrosis after completing radiotherapy. Oncological patients whose treatment consisted only of surgical procedures, without irradiation or chemotherapy, have no indications to postpone the commencement of orthodontic treatment. ${ }^{23}$

Comparing the first patient, who underwent chemotherapy and radiotherapy, with the other one, who was subjected only to chemotherapy treatment, it can be concluded that radiotherapy directed at the craniofacial region at a developmental age significantly worsens the prognosis. It inhibits or significantly delays the development of the permanent teeth buds, disrupts the development of the craniofacial bone - which may lead to an unsightly asymmetry of the face - and it additionally contributes to disrupted enamel mineralization.

Due to the possible consequences of cancer therapy - increased susceptibility to infections, reduced immunity and a tendency for mucous membrane atrophy, not to mention xerostomia - appliances with the lowest possible irritation of the mucous membrane should be selected in case of such complications. When salivary secretion is disturbed, the risk of caries development is additionally increased; thus, more frequent fluoridation and more frequent oral hygiene check-ups are recommended. ${ }^{24}$ In the cases of the patients presented herein, there was no 
disturbance of salivary secretion or damage to the oral mucosa. The tolerance of both the block appliance used to treat the first patient and of the prosthetic plates in the other patient was very good.

It is important to assess the rate of growth in the patient and to consider administering growth hormone to normalize the pattern of craniofacial bone growth. ${ }^{25}$ Craniofacial bone development disorders can be observed in the first patient, in whom the location of the tumor itself influenced the deformations. The tumor infiltrating the basal area of the skull, the effects of surgical tumor resection and radiation therapy directed at the craniofacial region all contributed to the asymmetry of the eye sockets, reduction in the length of the face and inhibited development of the mandible. On the other hand, the collapse of the subnasal area and the shortening of the lower face in the second patient were mainly due to the premature loss of the deciduous teeth, atrophy of the alveolar process of the maxilla and the alveolar part of the mandible, and reduced height of occlusion. However, skeletal changes occurring as the patient grew cannot be ruled out.

Symptoms of temporomandibular joint dysfunction are observed in patients undergoing the combination therapy of chemotherapy and radiotherapy of the entire body. $\mathrm{Pa}$ tient B.D. in this study suffered from lock-jaw, which subsided with the use of a relieving appliance. The reduced extent of the mandibular abduction caused difficulties in obtaining impressions and adjusting the orthodontic appliance.

Oncological patients do not require special orthodontic procedures, yet the high risk of complications encourage the planning of orthodontic treatment with the least burden. It is recommended to use low force in order to minimize the risk of root resorption (since the roots have already been shortened as a result of radiotherapy), to accept the compromised results of simple mechanical treatment, and to complete orthodontic treatment earlier than usual or to treat only the upper dentition. ${ }^{26,27}$

Orthodontic treatment must include a risk assessment regarding the loss of the teeth with significantly shortened roots. There are no contraindications to implantation in patients with a medical history of a neoplastic disease, but due to the continued growth of a minor patient, it must be postponed. Patients should have any missing teeth replaced with prostheses and plate prostheses until fixed, implant-based prosthetic restorations can be provided. ${ }^{28-30}$ The example of patient J.G. illustrates the problems which may appear in oncological patients with extensive tooth deficiencies. The loss of the alveolar processes in the maxilla and the alveolar region of the mandible resulted in unfavorable cconditions for the prosthetic base. Initially, the stabilization of the complete superior prosthesis and partial inferior prosthesis was obtained, allowing the patient to use prostheses, but not at mealtimes - the patient was unable to adapt to eating with prostheses.
Unfortunately, there was a rapid loss of the initial prosthesis stabilization due to the patient's growth and to the progressive eruption of the permanent teeth.

As cooperation with the patient is limited and he is reluctant to undergo clinical procedures, it is difficult to prepare new prosthetic restorations at the intervals of several months, though the patient does regularly report to follow-up appointments for the tooth eruption to be observed. The eruption of the first permanent molars should improve the stabilization of subsequent prostheses.

\section{Conclusions}

Based on the analysis of the available publications, it can be concluded that among patients who were subjected to oncological treatment before they reached the age of 6 years, the following complications of the masticatory system are most commonly observed: hypodontia, abnormal structure of the tooth roots, enamel abnormalities, premature loss of the permanent teeth, xerostomia, and gingivitis. Radiotherapy and chemotherapy are independent risk factors for adverse dental and facial bone effects. Patients undergoing oncological treatment at the age of $<6$ years should receive adequate and long-term monitoring, owing to the possibility of distant effects of the underlying disease and its treatment. Radiotherapy of the head and neck region administered to a growing patient can significantly worsen their prognosis and may result in a number of irreversible complications.

\section{ORCID iDs}

Izabela Michalak (D) https://orcid.org/0000-0002-0223-4279 Dorota Kuśmierczyk (D) https://orcid.org/0000-0003-3880-6045 Katarzyna Bluj-Komarnitka (i) https://orcid.org/0000-0001-8664-6299 Sadri Rayad (1) https://orcid.org/0000-0003-3415-369X

Małgorzata Zadurska (1) https://orcid.org/0000-0002-2303-4102

\section{References}

1. Ward E, DeSantis C, Robbins A, Kohler B, Jemal A. Childhood and adolescent cancer statistics, 2014. CA Cancer J Clin. 2014;64(2):83-103.

2. Dahllöf G, Huggare J. Orthodontic considerations in the pediatric cancer patient: A review. Semin Orthod. 2004;10(4):266-276.

3. Maciel JC, de Castro CG Jr, Brunetto AL, Di Leone LP, da Silveira HE. Oral health and dental abnormalies in patients treated for leukemia in childhood and adolescence. Pediatr Blood Cancer. 2009;53(3):361-365.

4. Hölttä P, Alaluusua S, Saarinen-Pihkala UM, Wolf J, Nyström M, Hovi L. Long-term adverse effects on dentition in children with poor-risk neuroblastoma treated with high-dose chemotherapy and autologous stem cell transplantation with or without total body irradiation. Bone Marrow Transpl. 2002;29(2):121-127.

5. Olczak-KowalczykD, Krasuska-Sławińska E, Brożyna A, Turska-Szybka A, Dembowska-Bagińska B. Dental caries in children and adolescents during and after antineoplastic chemotherapy. $J$ Clin Pediatr Dent. 2018;42(3):225-230.

6. Macleod RI, Welbury RR, Soames JV. Effects of cytotoxic chemotherapy on dental development. J Royal Soc Med. 1987;80(4):207-209.

7. Hwang SY, Yoon RK. Developmental dental defects linked to chemoradiotherapy: A case report. J Clin Pediatr Dent. 2011;35(3):309-314.

8. Otmani N. Oral and maxillofacial side effects of radiation therapy on children. J Can Dent Assoc. 2007;73(3):257-261. 
9. Jaffe N, Toth BB, Hoar RE, Ried HL, Sullivan MP, McNeese MD. Dental and maxillofacial abnormalities in long-term survivors of childhood cancer: Effects of treatment with chemotherapy and radiation to the head and neck. Pediatrics. 1984;73(6):816-823.

10. Dahllöf G, Rozell B, Forsberg CM, Borgström B. Histologic changes in dental morphology induced by high dose chemotherapy and total body irradiation. Oral Surg Oral Med Oral Pathol. 1994;77(1):56-60.

11. Krasuska-Sławińska E, Dębowska-Bagińska B, Brożyna A, OlczakKowalczyk D, Czarnowska E, Sowińska A. Changes in the chemical composition of mineralised teeth in children after antineoplastic treatment. Contemp Oncol (Pozn). 2018;22(1):37-41.

12. Darzy KH, Shalet SM. Radiation-induced growth hormone deficiency. Horm Res. 2003;59(Suppl 1):1-11.

13. Hicks J, Flaitz C. Rhabdomyosarcoma of the head and neck in children. Oral Oncol. 2002;38(5):450-459.

14. Maguire A, Welbury RR. Long-term effects of antineoplastic chemotherapy and radiotherapy on dental development. Dent Update. 1996;23(5):188-194.

15. Krasuska-Sławińska E, Brożyna A, Dembowska-Bagińska B, OlczakKowalczyk D. Antineoplastic chemotherapy and congenital tooth abnormalities in children and adolescents. Contemp Oncol (Pozn). 2016;20(5):394-401.

16. Forsberg CM, Krekmanova L, Dahllöf G. The effect of growth hormone therapy on mandibular and cranial base development in children treated with total body irradiation. Eur J Orthod. 2002;24(3):285-292.

17. Neill CC, Migliorati C, Trojan T, et al. Experience and expertise regarding orthodontic management of childhood and adolescent cancer survivors. Am J Orthod Dentofacial Orthop. 2015;148(5):765-770.

18. Krasuska-Sławińska E, Brożyna A, Dembowska-Bagińska B, OlczakKowalczyk D. Factors influencing caries incidence in permanent teeth in children/adolescents under and after anti-neoplastic treatment. Contemp Oncol (Pozn). 2016;20(1):45-51.

19. Maier H, Zöller J, Herrmann A, Kreiss M, Heller WD. Dental status and oral hygiene in patients with head and neck cancer. Otolaryngol Head Neck Surg. 1993:108(6):655-661.

20. Karolewska E, Konopka T. Preventive-therapeutic dental care protocol in children with leukemia [in Polish]. Czas Stomatol. 2006;59(4):245-252.

21. Radej I, Bugała-Musiatowicz B, Szarmach I. Grodzka I. Planning of orthodontic treatment in patients with a history of neoplastic disease - case reports [in Polish]. Orthod Forum. 2013;9(40):267-283.

22. Kumar S, Valiathan A, Jayaswal P, Sivakumar A. Class II treatment of an adolescent patient with a history of acute lymphocytic leukemia. J Clinic Orthod. 2011;45(12):661-665.

23. Dahllöf G, Jönsson A, Ulmner M, Huggare J. Orthodontic treatment in long-term survivors after pediatric bone marrow transplantation. Am J Orthod Dentofacial Orthop. 2001;120(5):5459-5465.

24. Nemeth O, Hermann P, Kivovics P, Garami M. Long-term effects of chemotherapy on dental status of children cancer survivors. Pediatr Hematol Oncol. 2013;30(30):208-215.

25. Schweyen R, Hey J, Franzel W, Vordermark D, Hildebrandt G, Kuhnt T. Radiation-related caries: Etiology and possible preventive strategies. What should the radiotherapist know? Strahlenther Onkol. 2012;188(1):21-28.

26. Oğuz A, Cetiner S, Karadeniz C, Alpaslan G, Alpaslan C, Pinarli G. Long-term effects of chemotherapy on orodental structures in children with non-Hodgkin's lymphoma. Eur J Oral Sci. 2004;112(1):8-11.

27. Burden D, Mullally B, Sandler J. Orthodontic treatment of patients with medical disorders. Eur J Orthod. 2001;23(4):363-372.

28. Buglione M, Cavagnini R, Di Rosario F, et al. Oral toxicity management in head and neck cancer patients treated with chemotherapy and radiation: Dental pathologies and osteoradionecrosis (Part 1) literature review and consensus statement. Crit Rev Oncol Hematol. 2016;97:131-142.

29. Niewald M, Fleckenstein J, Mang K, Holtmann H, Spitzer WJ, Rübe C. Dental status, dental rehabilitation procedures, demographic and oncological data as potential risk factors for infected osteoradionecrosis of the lower jaw after radiotherapy for oral neoplasms: A retrospective evaluation. Radiat Oncol. 2013;8:227.

30. Reuther T, Schuster T, Mende U, Kübler A. Osteoradionecrosis of the jaws as a side effect of radiotherapy of head and neck tumor patients - a report of a thirty year retrospective review. Int J Oral Maxillofac Surg. 2003;32(30):289-295. 